ФИЛОНЕНКО Виктор Иванович - доктор социологических наук, профессор; руководитель Центра социально-политических исследований Южного федерального университета (344006, Россия, 2. Ростов-на-Дону, ул. Большая Садовая, 105/42; soc-centr-sfedu@yandex.ru)

КИЕНКО Татьяна Сергеевна - кандидат социологических наук, доцент Южного федерального университета (344006, Россия, г. Ростов-на-Дону, ул. Большая Садовая, 105/42; tatyanakienki@mail.ru)

\title{
СОЦИАЛЬНЫЕ ЦЕННОСТИ И ПРОБЛЕМЫ ЗДОРОВЬЕСБЕРЕЖЕНИЯ СТУДЕНЧЕСКОЙ МОЛОДЕЖИ
}

Аннотация. В работе представлены результаты исследования социальных ценностей и проблем здоровьесбережения современной студенческой молодежи, проведенного Центром социально-политических исследований Южного федерального университета. Полученные данные позволяют констатировать положительную динамику формирования здорового образа жизни, рост популярности идеи и практик ЗОЖ, отказа от вредных привычек среди студенческой молодежи. Однако отмечается парадокс различия оценок роли и популярности здорового образа жизни студенчеством разных типов вузов и направлений в статике и динамике. Одной из актуальнейших проблем видится отмеченная связь роста закрепленных вредных привычек со снижением уровня материального достатка студентов. Отмечен парадокс роста роли ЗОЖ среди современной студенческой молодежи на фоне доминанты инструментальной ценности здоровья над терминальной, что определяет реактивность, тактический, а не стратегический характер здоровьесбережения значительного числа студенческой молодежи.

Ключевые слова: студенческая молодежь, здоровье, здоровый образ жизни, социальные ценности здоровья, здоровьесбережение, здоровьесберегающие практики

\section{Введение}

Исследования последних 15 лет свидетельствуют об устойчивой и значительной положительной динамике отношения молодежи к здоровью, демонстрируют рост ценности здоровья и ЗОЖ, оценок его значения как фактора жизненного успеха среди студенчества. Вместе с тем исследователи заявляют о парадоксах в отношении молодежи к здоровью и ЗОЖ: отмечается преимущественно декларативный характер здорового образа жизни молодежи, феномен возложения ответственности за свое здоровье на государство и общество.

Двойственность социального статуса студенчества, разрыв желаемого и доступного, предпочтений и возможностей приводят к рискам социальных и внутренних конфликтов, противоречивости выбора, смешению социальных ценностей, установок, целей и практик.

Важным аспектом в социологическом объяснении здоровьеразрушающих и здоровьесберегающих практик молодежи является социальный характер потребления [Бодрийяр 2000]. Рост моды на ЗОЖ, увлечение здоровым питанием, косметической медициной или спортом как форма социального поведения, потребления и атрибут статуса не всегда ведут к пониманию терминальной ценности здоровья. В современном «обществе риска» в условиях ценностного хаоса, множественности доступных ценностей, выбор которых затруднен перегруженностью объектов выбора [Бек 2000], человек не в силах отделить ценности истинные от ложных, навязанных СМИ, массовой культурой, рекламой, статусными атрибутами или узостью собственного опыта.

Описание типичных и специфических социальных ценностей и проблем здоровьесбережения современной студенческой молодежи основаны на материалах эмпирического мониторингового исследования «Противоречия и парадоксы социализации студенческой молодежи в условиях транзитивности совре- 
менного российского общества», проведенного Центром социально-политических исследований Южного федерального университета под руководством профессора В.И. Филоненко в 2016 г. (грант № ВнГр-07/2017-27). Основными методами исследования выступали анкетирование, фокусированные интервью, метод фокус-групп, анализ документов, наблюдение. Один из блоков анкеты был посвящен анализу отношения студентов к здоровью. Общая выборка охватила студентов 23 российских вузов / филиалов вузов семи регионов РФ и 4 федеральных университетов - К(П)ФУ, СКФУ, УрФУ и ЮФУ. Ряд вопросов, касающихся представлений о ЗОЖ, изучался в ходе аналогичных исследований в 2006 и 2011 гг., что позволяет рассматривать динамику отдельных показателей ${ }^{1}$.

\section{Ценности здоровья, практики здоровьесбережения}

\section{и здоровьеразрушения в студенческой среде}

Из 4387 студентов вузов различного уровня и профиля, опрошенных в 2016 г., 55,7\% отметили, что идея здорового образа жизни в настоящее время «очень популярна» среди студенчества, 29,7\% - «не очень популярна», 3,9\% - «совсем не популярна», 10,7\% затруднились с ответом. Распределение показало, что вариант «очень популярна» выбрали 50,1\% студентов федеральных вузов - К(П)ФУ, СКФУ, УрФУ, ЮФУ, 55,3\% студентов вузов Ростовской обл. и $57,4 \%$ студентов вузов Южного федерального округа в целом (идея здорового образа жизни менее популярна среди студентов федеральных университетов, что авторы склонны объяснять более критичным мышлением учащихся данных вузов). В период 2006-2016 гг. отмечается тенденция роста ценности 3ОЖ в оценках студентов всех типов вузов, но в учебных заведениях естественногуманитарных направлений популярность $30 Ж$ возросла в 1,7 раза (с $31,7 \%$ в 2006 г. до 32,6\% в 2011 г. и до 54,5\% в 2016 г.), в инженерно-технологических - в 2,3 раза (с 22,4\% в 2006 г. до 37,6\% в 2011 г. и до 52,1\% в 2016 г.), а в сельскохозяйственных - в 3,8 раза (в 2006 г. - 18,3\%, в 2011 г. - 38,3\%, а в 2016 г. - 68,7\%). Пропорционально наблюдается и рост оценок своего здоровья среди студентов инженерно-технологических и сельскохозяйственных направлений с 2006 по 2016 г. Оценивают состояние своего здоровья как хорошее в 2016 г. от 51,5\% до 62,6\% респондентов, более трети - как удовлетворительное, от 5 до 8\% - как плохое. Отмечаются особенности по направлениям подготовки: самые высокие отзывы о своем здоровье как о хорошем и самые низкие - как о плохом в 2016 г. показывают студенты экономических (62,6\% и 5,5\% соответственно), сельскохозяйственных $(60,6 \%$ и $5,58 \%)$ и инженерно-технологических $(60,4 \%$ и 5,3\%) направлений. Самые значительные показатели оценки своего здоровья как плохого демонстрируют учащиеся социально-гуманитарных $(8,6 \%)$, медицинских $(8,1 \%)$, архитектурного и дизайнерского $(7,8 \%)$ и психолого-педагогического $(7,5 \%)$ направлений.

\footnotetext{
${ }^{1}$ В ноябре - декабре 2006 г. Межвузовский центр социологических исследований Совета ректоров вузов Ростовской области под руководством В.И. Филоненко провел социологическое исследование «Социализация и воспитание студентов вузов» методами анкетирования, в основном квотированного (были опрошены 2236 студентов 1-5 курсов обучения 11 вузов, 469 экспертов 10 вузов), и углубленного фокусированного интервью (487 студентов 5 вузов г. Ростова-на-Дону и Ростовской обл.). Логическим продолжением стало проведенное в мае-ноябре 2011 г. региональное исследование социализации и воспитания студенческой молодежи вузов Ростовской обл. (осуществлено по сопоставимой программе Социологическим центром мониторинга, диагностики и прогнозирования социального развития ЮФУ. Выборка охватила 13 государственных и 3 негосударственных вуза, опрошены 4029 студентов (анкетирование - 4013 чел., фокус-группы - 16 чел.); 953 эксперта (анкетирование - 937 чел., фокусгруппы - 16 чел.) - проректоры и заместители деканов по воспитательной работе, кураторы учебных групп, деканы и заведующие кафедрами, преподаватели общенаучных, социально-гуманитарных и выпускающих кафедр; 406 работодателей, которые представляют 41 территорию 12 регионов РФ.
} 
Ответы на вопрос об отношении студентов к курению показали следующее: в 2016 г. 85,8\% респондентов заявили, что не курят, около $15 \%$ - курят, в т.ч. $8,2 \%$ - несколько сигарет в день, 3,1\% - до 10 сигарет в день, 2,9\% - заядлые курильщики. В федеральных университетах в сравнении с вузами Ростовской обл. и вузами ЮФО зафиксирован наибольший процент некурящих и наименьший процент студентов, курящих до 10 сигарет в день, что свидетельствует о состоятельности выдвинутой выше гипотезы о повышенной критичности мышления студентов этих вузов. Анализ данных в 2006, 2011, 2016 гг. позволяет говорить об устойчивой тенденции сокращения курения в студенческой среде и о прямой корреляции курения с оценками своего здоровья. Заметнее всего выросло число некурящих и существенно снизился процент заядлых курильщиков среди студентов инженерно-технологических (некурящих - от 67\% до 84,0\%, заядлых курильщиков - от $7 \%$ до $3,1 \%$ ) и сельскохозяйственных (некурящих - от 58,6\% до 85,3\%, заядлых курильщиков - от $14,6 \%$ до 2,6\%) направлений. Именно среди студентов указанных направлений в отмеченный период существенно выросли оценки своего здоровья как хорошего и снизились его оценки как плохого.

Употребление алкоголя в студенческой среде также указывает на связь вредных привычек с оценкой студентами своего здоровья. В 2016 г. 41,9\% респондентов отметили, что вообще не употребляют спиртное, 43,9\% - только по праздникам, 12,0\% - несколько раз в месяц, 2,2\% употребляют спиртные напитки несколько раз в неделю. Полученные нами данные практически в полной мере сообразуются с результатами эмпирического исследования в МГУ и РУДН по употреблению алкоголя студентами [Пузанова, Тертышникова 2017: 90]. Хотя в целом процент студентов, употребляющих алкоголь несколько раз месяц и несколько раз в неделю, на первый взгляд, невелик, но, во-первых, нужно учесть моральную нагруженность вопроса и высокую вероятность желания студентов продемонстрировать перед исследователями лучшие качества и скрыть острые проблемные моменты; во-вторых, даже согласно полученным данным, среди опрошенных 4387 студентов 523 чел. часто и 96 чел. постоянно употребляют алкоголь (с большой долей вероятности последние страдают алкоголизмом).

Итак, здоровье и ЗОЖ ассоциируются в сознании студентов в первую очередь с отсутствием вредных привычек (что верно, но не достаточно). Популярность ЗОЖ среди студентов прямо коррелирует с наличием у них вредных привычек, особенно с их закрепленными формами: в подгруппе некурящих и непьющих студентов идея ЗОЖ популярнее, чем среди курящих или пьющих. Но гораздо важнее, что среди студентов, считающих идеи ЗОЖ непопулярными, в 2-3 раза выше процент употребляющих алкоголь очень часто и постоянно курящих. Гендерные различия в отношении к алкоголю и курению также имеют место (что подтверждает общеизвестные гендерные особенности девиантных проявлений в обществе в целом): идея здорового образа жизни значительно популярнее среди девушек, чем среди юношей. Среди девушек существенно выше процент некурящих, в 3-4 раза меньше курящих много и часто, чем среди юношей; близкую, но не столь существенную тенденцию можно заметить и в отношении к алкоголю.

В процессе обучения от курса к курсу неуклонно на 2-3\% (и более) растет число студентов, считающих идеи ЗОЖ важными. Однако на фоне роста популярности ЗОЖ студентов, не употребляющих алкоголь, с каждым годом обучения становится на 1-2\% меньше в пользу употребляющих спиртное редко или несколько раз в месяц. Такую динамику можно объяснить процессами физиологического, социального и психологического взросления: молодые люди, не 
употреблявшие алкоголь в родительской семье, начинают практиковать «взрослый» образ жизни. Отмеченный нами феномен вступает в противоречие с данными исследования практик потребления алкоголя среди студентов московских вузов [Артемьева и др. 2017: 221], что актуализирует задачу дальнейшего уточнения обнаруженного противоречия (в т.ч. поиск отличий в отношении к ЗОЖ студентов провинциальных и столичных вузов). С 2006 г. более чем в 2 раза увеличилось число студентов, ведущих трезвый образ жизни, в естественногуманитарных и инженерно-технологических вузах и в 4,7 раза - в сельскохозяйственных. За 10 лет устойчиво сократилось и число употребляющих алкоголь по праздникам, несколько раз в месяц, несколько раз в неделю во всех типах вузов.

Среди студентов, разделяющих коллективные ценности, на 3-4\% выше процент курящих (всех категорий) и на 3-4\% ниже численность некурящих; на 3-5\% больше принимающих алкоголь несколько раз в месяц или неделю и меньший процент непьющих; наибольший процент употребляющих ненормативную лексику. Именно в этой подгруппе значимость идеи ЗОЖ ниже, чем среди остальных студентов: вредные привычки являются в определенной степени продуктом «дифференциальной ассоциации», влияния референтной группы, «хорошей компании».

Свободное время является частью образа жизни: посещают спортклубы, секции, тренировки 37,9\% респондентов, занимаются в различных кружках, клубах по интересам (музыка, танцы и т.д.) - 11,4\%, проводят время на природе, гуляют - 38,8\%. Спорт и физкультура - не самая распространенная форма досуга: гораздо чаще студенты ходят в кино $(60,2 \%)$, слушают музыку $(59,1 \%)$, встречаются и общаются с друзьями $(57,3 \%)$, читают книги $(56,2 \%)$, смотрят фильмы $(51,2 \%)$. Тем не менее играют в компьютерные игры и увлекаются Интернетом студенты реже, чем посещают спортзалы. Большинство студентов заявляют об удовлетворенности занятиями физкультурой и спортом в вузе, и первыми здесь выступают учащиеся сельскохозяйственных вузов. Относительно новой тенденцией является рост значимости молодежных субкультур, акцентирующих внимание на формировании здорового образа жизни -идеология стрейт-эйджа, скейтеров, роллеров, трейсеров (паркур), воркаута (турники) и пр. Среди студенческой молодежи эти субкультуры пользуются популярностью и одобрением, многие респонденты считают их конструктивными, приносящими пользу молодежи и обществу в целом.

Анализируя социальные ценности здоровья студенческой молодежи, стоит обратить внимание на определение положительных и отрицательных черт своего поколения. Для значительной доли студенчества положительными особенностями молодого поколения являются инструментальные ценности индивидоцентристского типа: самостоятельность (от 39 до 47\% респондентов в зависимости от направления подготовки), целеустремленность (от 36 до 41\%), жизненная активность и оптимизм (от 27 до 43\%). От четверти до трети студентов к числу положительных качеств отнесли интеллект и творчество; от 12 до $20 \%$ называют трудолюбие и предприимчивость. Ценности социоцентристского типа, терминального порядка разделяются частью студентов: от 10 до 17\% называют уважение к старшим, от 7 до 20\% - патриотизм; от 9 до $16 \%$ - коллективизм, от 6 до 12\% - стремление к знаниям, культуре, гуманизм, от 5 до 8\% - честь и порядочность. К числу отрицательных черт своего поколения около половины учащихся всех направлений отнесли алкоголизм, пьянство, наркоманию, курение (от 44,6\% гуманитариев до 57\% будущих медиков). Значительная часть указала эгоизм, корыстолюбие (от 32 до 40\%), бесцельное существование, потребительское отношение к жизни, пассивность, иждивенчество, лень и раз- 
гильдяйство (от 29 до 42\%). Около четверти называют аморальность, распущенность, разврат, хамское поведение, грубость, бескультурье. Пятая часть относит к негативным чертам агрессивность, цинизм, жестокость, преступность, лицемерие, безответственность, лживость; около $15 \%$ - бездуховность. Определить отрицательные черты студентам легче, чем положительные (затруднились назвать положительные черты от $11,0 \%$ до 20,7\% респондентов, отрицательные - от 4 до 12\%). Доминирование ценностей инструментальных над терминальными, индивидоцентристских - над социоцентристскими, прагматических над духовными свидетельствует о том, что ЗОЖ, отрицание алкоголизма, курения, наркомании скорее следует считать инструментом жизненного успеха, атрибутом статуса, данью моде, общепринятым стандартам и стереотипам, но не всегда - признаком сознательного восприятия здоровья как терминальной социальной ценности. Имеет место недостаток целостности восприятия ЗОЖ как системы физического, психического, социального и духовного здоровья (вредные привычки, физическое нездоровье более очевидны; социально-психологические и духовные аспекты ЗОЖ меньше подвергаются рефлексии).

Поиск связей отношения к ЗОЖ и наличия вредных привычек с уровнем материального достатка студентов показал, что процент курящих в подгруппах тем больше, чем ниже уровень материального положения респондентов (особенно это касается много курящих); непьющих студентов поступательно все больше в подгруппах учащихся, лучше обеспеченных материально (см. табл. 1). Кроме самого факта, что среди студенчества есть люди, едва сводящие концы с концами и недоедающие, живущие в нищете, требуют особого внимания данные, что среди студентов, употребляющих алкоголь несколько раз в неделю, в 4 раза больше живущих на грани нищеты, чем бедных, и в 10 раз больше, чем среди живущих в достатке или в подгруппах обеспечивающих себя с трудом.

\section{Выводы и рекомендации}

Данные исследований 2006-2016 гг. позволяют констатировать положительную динамику формирования здорового образа жизни, отказа от вредных привычек, рост популярности идеи и практик ЗОЖ, числа приверженцев здорового образа жизни среди студенческой молодежи, существенное превышение в последние 10 лет темпов роста «запаздывающих» ранее здоровьесберегающих ценностей и практик среди студентов сельскохозяйственных и инженернотехнологических вузов. Однако отмечается парадокс различия оценок роли и популярности здорового образа жизни студенчеством разных типов вузов и направлений. Здоровье и ЗОЖ ассоциируются в сознании студентов в первую очередь с отсутствием вредных привычек (что верно, но не достаточно).

Исследование обнаруживает тесную связь вредных привычек с оценкой студентами своего здоровья: чем чаще в подгруппах студентов практикуются вредные привычки (алкоголь, курение), чем глубже степень пристрастия к вредным привычкам, тем ниже в данной подгруппе оценки собственного здоровья. Вредные привычки являются в некоторой степени продуктом «дифференциальной ассоциации», референтной группы, результатом «хорошей компании» и в значительной степени - продуктом социального неравенства, экономического расслоения, низкого статуса. Одной из актуальнейших проблем является связь роста закрепленных вредных привычек со снижением уровня материального достатка студентов. И данная проблема выступает в геометрической прогрессии: устойчивый алкоголизм и курение в разы чаще присущи молодежи, живущей в бедности и нищете.

Следует также отметить парадокс роста роли ЗОЖ среди молодежи на фоне доминирования инструментальной ценности здоровья над терминальной. 
Таблица 1

Корреляция оценки популярности ЗОЖ и наличия вредных привычек с материальным статусом респондентов (2016 г., в \% к числу опрошенных)

\begin{tabular}{|c|c|c|c|c|c|}
\hline \multirow{3}{*}{ Варианты ответов } & \multicolumn{5}{|c|}{$\begin{array}{c}\text { Как бы Вы охарактеризовали свое нынешнее материальное } \\
\text { положение? Живете ли Вы: }\end{array}$} \\
\hline & 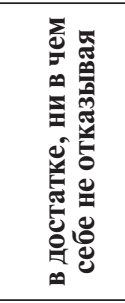 & 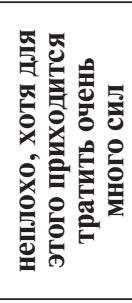 & 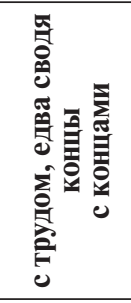 & 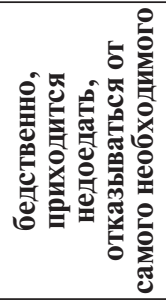 & 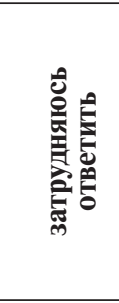 \\
\hline & $\begin{array}{c}\% \text { по } \\
\text { столбцу }\end{array}$ & $\begin{array}{c}\text { \% по } \\
\text { столбцу }\end{array}$ & $\begin{array}{c}\text { \% по } \\
\text { столбцу }\end{array}$ & $\begin{array}{l}\text { \% по } \\
\text { столбцу }\end{array}$ & $\begin{array}{l}\text { \% по } \\
\text { столбцу }\end{array}$ \\
\hline \multicolumn{6}{|c|}{ Курите ли Вы? } \\
\hline Нет, не курю & 88,2 & 86,5 & 76,7 & 73,7 & 86,5 \\
\hline $\begin{array}{l}\text { Да, несколько сигарет } \\
\text { в день }\end{array}$ & 6,9 & 8,3 & 12,1 & 5,3 & 7,8 \\
\hline Да, до 10 сигарет в день & 2,9 & 2,9 & 5,5 & 5,3 & 2,5 \\
\hline Да, до пачки в день & 2,0 & 2,4 & 5,7 & 15,8 & 3,2 \\
\hline \multicolumn{6}{|c|}{ Употребляете ли Вы спиртные напитки? } \\
\hline Нет & 50,0 & 39,0 & 31,3 & 35,7 & 49,5 \\
\hline $\begin{array}{l}\text { Употребляю редко, по } \\
\text { большим праздникам }\end{array}$ & 38,1 & 46,8 & 49,1 & 30,4 & 39,1 \\
\hline Несколько раз в месяц & 10,1 & 13,0 & 14,5 & 12,5 & 8,5 \\
\hline Несколько раз в неделю & 1,9 & 1,2 & 5,1 & 21,4 & 2,8 \\
\hline \multicolumn{6}{|c|}{$\begin{array}{l}\text { Популярна ли, на Ваш взгляд, в настоящее время в студенческой среде } \\
\text { идея здорового образа жизни? }\end{array}$} \\
\hline Очень популярна & 61,2 & 55,3 & 49,1 & 50,9 & 46,8 \\
\hline Не очень популярна & 26,9 & 30,4 & 37,1 & 22,8 & 25,6 \\
\hline Совсем не популярна & 3,1 & 3,6 & 6,6 & 14,0 & 4,1 \\
\hline Затрудняюсь ответить & 8,8 & 10,6 & 7,2 & 12,3 & 23,5 \\
\hline
\end{tabular}

Отношение к здоровью, оценка здоровья и ценность здоровьесбережения связаны с тенденциями роста «моды на здоровье», что сопряжено с некритичностью, нерефлексивностью здоровьесберегающих практик, рисками злоупотреблений и опасностей безрефлексивного принятия моды на ЗОЖ, «временностью» инструментальных модных здоровьесберегающих практик. Очевидно, что популярность идей здоровьесбережения повышает ценность здоровья, оценку собственного здоровья, мотивацию к ЗОЖ и развитие здоровьесберегающих практик, однако доминирование инструментальной ценности здоровья над терминальной сопряжено с нерефлексивностью и низким уровнем личной ответственности за свое здоровье, наличием парадокса в отношении здоровья 
как противоречивости мнений, суждений, ориентаций и действий, одновременно существующих в сознании и поведении одних и тех же людей [Тощенко 2001]. Одновременно это усугубляется влиянием социально-экономической стратификации и двойственности статуса студента, социальным характером потребления и образа жизни студенческой молодежи в целом, определяя реактивность, тактический, а не стратегический характер здоровьесбережения значительного числа студенческой молодежи.

\title{
Список литературы
}

Артемьева Н., Богданов М., Лебедев Д., Назимова А. 2017. Факторы, определяющие тип потребления алкоголя среди студентов. - Вестник общественного мнения: Данные. Анализ. Дискуссии. № 1-2(124). С. 203-233.

Бек У. 2000. Общество риска. На пути к другому модерну. М.: ПрогрессТрадиция. 384 с.

Бодрийяр Ж. 2000. Прозрачность зла (пер. с фр. Л. Любарской, Е.Марковской). М.: Добросвет. 387 с.

Пузанова Ж.В., Тертышникова А.Г. 2017. Особенности образа жизни и отношения к здоровью российских студентов (на примере МГУ и РУДН). - Социс. Социологические исследования. № 8. С. 88-93.

Тощенко Ж.Т. 2001. Парадоксальный человек. М.: Гардарики. 398 с.

FILONENKO Victor Ivanovich, Dr.Sci. (Soc.), Professor; Head of the Center for Social and Political Studies, Southern Federal University (105/42 Bolshaya Sadovaya St, Rostov-on-Don, Russia, 344006; soc-centr-sfedu@yandex.ru) KIENKO Tat'yana Sergeevna, Cand.Sci. (Soc.), Associate Professor of the Southern Federal University (105/42 Bolshaya Sadovaya St, Rostov-on-Don, Russia, 344006; tatyanakienki@mail.ru

\section{SOCIAL VALUES AND PROBLEMS OF HEALTH SAVING OF THE STUDENT YOUTH}

\begin{abstract}
The paper presents the results of a study conducted by the Center for Social and Political Studies to determine the social values and health problems of modern students, current health practices and significant social factors affecting their choice. The data obtained allow us to state the positive dynamics in the formation of a healthy lifestyle, in the rejection of bad habits, the growing popularity of the ideas and practices of healthy lifestyle, the number of adherents of a healthy lifestyle among students. The study reveals a close connection of health, health saving and health destroying practices with the students' assessment of their health. The most significant factors seem to reflect the socio-cultural trends of fashion for health and social inequality, economic stratification, low status. One of the most urgent problems is the marked connection of the growth of fixed bad habits with a decrease in the level of material prosperity of students. The authors consider paradox of the growing role of healthy lifestyle among young people against the background of dominance of instrumental value of health over the terminal, which determines the reactivity, tactical rather than strategic nature of health of a significant proportion of students.
\end{abstract}

Keywords: student youth, health, social values of health, health saving, health saving practices 